\title{
Effects of maternal obesity on early and long-term outcomes for offspring
}

This article was published in the following Dove Press journal:

Research and Reports in Neonatology

22 March 2014

Number of times this article has been viewed

Laura I Stirrat ${ }^{1,2}$

Rebecca M Reynolds ${ }^{2,3}$

'Medical Research Council Centre for Reproductive Health, Queens Medical Research Institute, University of Edinburgh, Edinburgh, UK; ${ }^{2}$ Tommy's Centre for Maternal and Fetal Health, Queens Medical Research Institute, University of Edinburgh, Edinburgh, UK; ${ }^{3}$ Endocrinology Unit, University/ British Heart Foundation Centre for Cardiovascular Science, Queens Medical Research Institute, University of Edinburgh, Edinburgh, UK
Correspondence: Rebecca M Reynolds Endocrinology Unit, University/BHF Centre for Cardiovascular Science, Queen's Medical Research Institute, 47 Little France Crescent, Edinburgh EHI 6 4TJ, UK

Tel +44 I 3 | 2426762

Fax +44 I3। 2426779

Email r.reynolds@ed.ac.uk
Abstract: The prevalence of maternal obesity has increased significantly in recent years, and obesity is currently the most common comorbidity of pregnancy. Pregnancies of obese women are often defined as "high-risk" for the purposes of clinical care, with many well documented risks to the mother and developing baby. Maternal physiology and metabolism is dysregulated in the context of obesity, which may contribute to some of the adverse outcomes during pregnancy. Furthermore, maternal obesity has been hypothesized to cause harmful effects for the developing baby through "early life programming." This review will examine evidence from human studies for outcomes of offspring from obese women during pregnancy, during labor, during the neonatal period, and later in life.

Keywords: pregnancy, short-term, physiology, metabolism, early life programming, neonatal complications, adverse intrauterine environment

\section{Introduction}

Obesity, defined as a body mass index (BMI) $>30 \mathrm{~kg} / \mathrm{m}^{2}$, has been described as the new worldwide epidemic, and as the prevalence of obesity increases, so does the number of women of reproductive age who are becoming overweight and obese. ${ }^{1}$ Obesity affects more than $30 \%$ of the antenatal population in the UK and is the most common comorbidity of pregnancy. ${ }^{2}$ Adverse pregnancy outcomes and short-term neonatal complications associated with maternal obesity have been well described, ${ }^{3-8}$ and for this reason, obese pregnant women receive high-risk care in many maternity units.

The link between an adverse intrauterine environment and disease later in life for the offspring has been well documented. ${ }^{9}$ Emerging data from experimental studies in animals and translational studies in humans have suggested that maternal obesity creates an adverse intrauterine environment for the developing fetus, with long-term "programmed" detrimental effects on the offspring. ${ }^{10,11}$ This review will focus on evidence from human studies to describe physiological changes during obese pregnancy and to summarize our current knowledge of the implications this may have for short- and long-term outcomes for offspring of obese mothers.

\section{Physiological changes in normal and obese pregnancy}

During normal pregnancy, changes take place in the maternal anatomy, physiology, endocrinology, and metabolism to prepare the mother for labor and delivery, and to provide essential nutrients for fetal growth and development. In obese pregnancy, the 
physiological adaptations differ from normal-weight women, reflecting physiology that is characteristic of obesity in the non-pregnant state; these changes are thought to contribute to an increased availability of fuel for fetal growth (Figure 1). Some of these changes can be attributed to the presence of a relative abundance of adipose tissue in obese pregnant women, which is now recognized as a metabolically active endocrine organ.

Adipose tissue is capable of producing a significant amount of pro-inflammatory cytokines such as tumor necrosis factor (TNF)- $\alpha$, interleukin (IL)-6, and adipokine hormones such as leptin and adiponectin. ${ }^{12}$ The relative increase in adipose hypertrophy and hyperplasia during obese pregnancy leads to dysregulated release of adipokines, plasma free fatty acids, and inflammatory markers. ${ }^{13,14}$ Adiponectin is exclusively produced by adipocytes, and lower levels are associated with insulin resistance independently from adiposity and other confounding factors. ${ }^{15,16}$ Although not released by the placenta, subcutaneous adipose tissue biopsies have shown that adiponectin mRNA (messenger ribonucleic acid) expression levels decrease over the course of pregnancy. ${ }^{17}$ The placenta is an important source of leptin, TNF- $\alpha$, and ILs. Analysis of placentas from obese pregnant women have found increased infiltration of macrophages and increased expression of inflammatory markers. ${ }^{18}$ Taken together, the relative increase in pro-inflammatory cytokine production by the adipose tissue and placentas of obese women may exaggerate physiological adaptations in pregnancy, ultimately leading to increased availability of nutrients for the fetus. This may also mean that offspring of obese women may be exposed to increased inflammation in utero, with potential harmful effects.

Fetal development requires the continuous availability of nutrients for transfer across the placenta. Glucose is the primary nutrient required for fetal growth, followed by amino acids and lipids. ${ }^{19}$

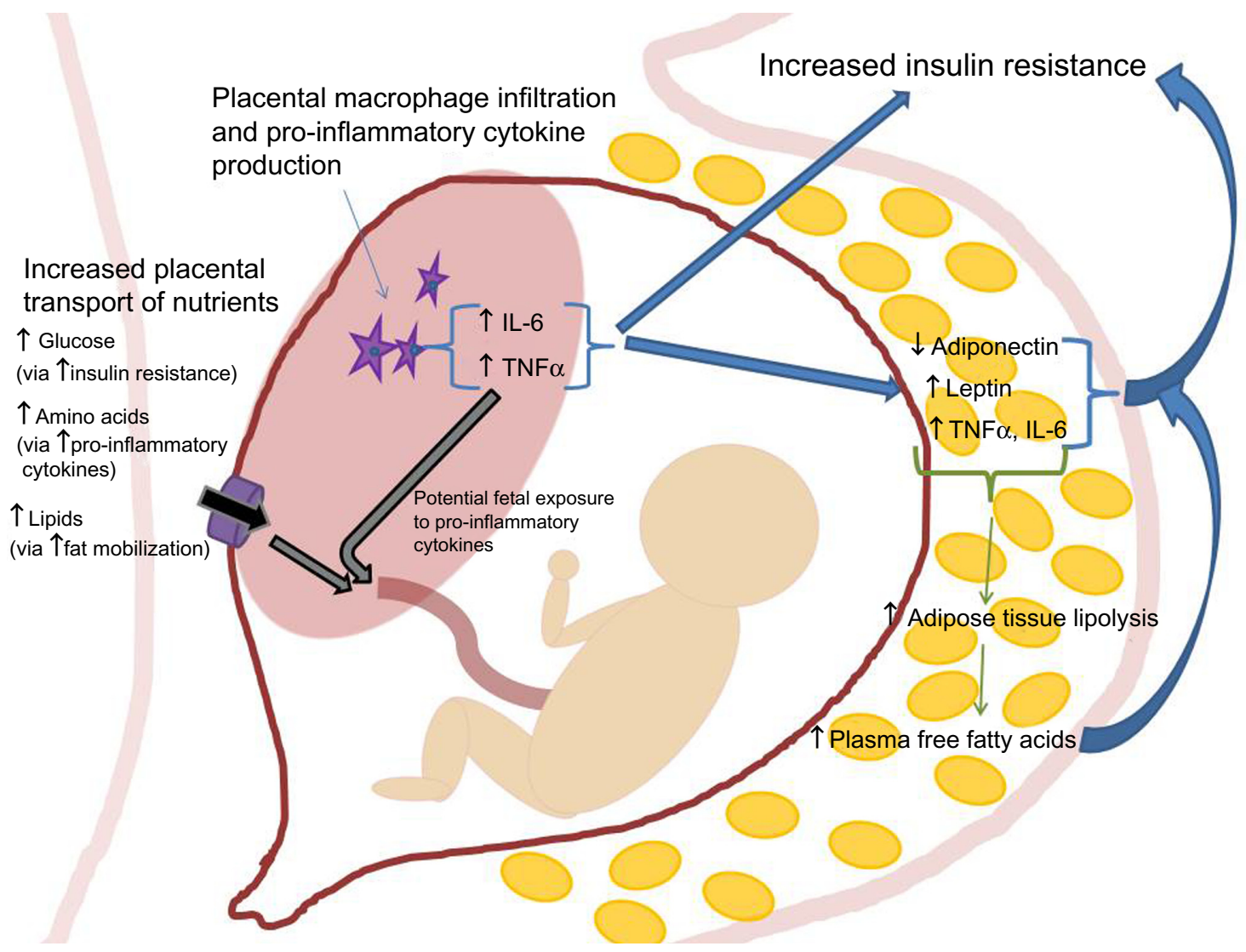

Figure I Placental and adipose tissue physiology in obese pregnancy.

Notes: Macrophage infiltration of the placenta is thought to contribute to increased production of pro-inflammatory cytokines (TNF- $\alpha$ and IL-6). These contribute to increased insulin resistance and increased lipolysis. The increase in plasma fatty acids as a result of lipolysis also increases insulin resistance. Altered transport of nutrients in obese pregnancy may include: increased glucose transport (via increased insulin resistance), increased amino acid transport (via pro-inflammatory cytokines) and increased lipid transport (via fat mobilization).

Abbreviations: IL, interleukin; TNF, tumor necrosis factor. 


\section{Glucose homeostasis}

Factors contributing to increased levels of maternal glucose during normal pregnancy include increased insulin resistance and increased levels of cortisol in the maternal circulation. Insulin sensitivity decreases by $50 \%-60 \%$ during normal pregnancy. ${ }^{17}$ Some of the factors associated with risk of increased insulin resistance are the same during pregnancy as in the non-pregnant state. These include being of non-European origin, ${ }^{20}$ lower pre-gravid levels of physical activity, ${ }^{21}$ and higher pre-pregnancy BMI. ${ }^{22}$ In obese pregnancy, insulin resistance is even more marked. ${ }^{23}$ This may be due to increased levels of TNF- $\alpha$, IL-6, leptin, and adiponectin, which are thought to contribute to insulin resistance in the non-pregnant state. ${ }^{24}$ In addition, the relative inability of insulin to suppress whole-body lipolysis results in an increase of plasma free fatty acids ${ }^{25}$ and exaggerated hyperlipidemia. ${ }^{26}$ These processes significantly increase fuel available for transport to fetuses of obese mothers.

Cortisol, which rises exponentially during pregnancy as a result of a dysregulated hypothalamic-pituitary-adrenal axis, ${ }^{27}$ has actions that include increasing insulin resistance and vasoconstriction. The cumulative effect of these could lead to proportionately greater uptake of glucose by the placenta. ${ }^{28}$ Other gestational specific adaptations and hormonal regulation related to insulin resistance during pregnancy are yet to be fully resolved. ${ }^{29}$

\section{Amino acids}

During pregnancy there is a net protein synthesis leading to tissue deposition in the mother and the fetus, and synthesis of other metabolically active compounds (eg, DNA [deoxyribonucleic acid], RNA, and neurotransmitters), thus the demand for amino acids is increased. ${ }^{30}$ It is thought that complex interactions between the maternal and fetal circulations, via the placenta, contribute to increased nutrient transport to the fetus in line with its metabolic demands. ${ }^{31}$ Reduced maternal amino acid concentrations have been associated with growth-restricted babies, ${ }^{32}$ and reduced amino acid oxidation in mid-late pregnancy has been linked with increased birth weight. ${ }^{33}$ This supports the notion that amino acid metabolism is important for fetal growth.

The effects of obesity on amino acid metabolism are not fully understood. In the non-pregnant state, obesity is associated with lower protein synthesis when compared with lean women, with no difference in protein oxidation. ${ }^{34}$ Visceral lean mass is positively correlated with maternal protein turnover. ${ }^{30}$ It has therefore been suggested that the anabolic response to pregnancy may be impaired in obese women, and that there may be mechanisms to limit fetal growth in a hyperinsulinemic and glucose-rich environment. ${ }^{35}$ However, a recent study found that activity of amino acid transporter system A in the placenta was positively correlated with birth weight. ${ }^{36}$ Furthermore, physiological concentrations of IL- 6 and TNF- $\alpha$ have also been shown to stimulate the activity of amino acid transporter system $\mathrm{A} \cdot{ }^{37}$ It has been suggested that in maternal obesity, the increased levels of IL- 6 and TNF- $\alpha$ in the placenta could stimulate system A transporter activity further, thus increasing amino acid transport to the fetus. ${ }^{38}$ Taken together, these data suggest that increased placental amino acid transport may contribute to fetal overgrowth in obese pregnancy.

\section{Lipid metabolism}

During normal pregnancy, lipid metabolism is altered to promote the accumulation of maternal fat stores in early-mid pregnancy and enhance fat mobilization in late pregnancy. ${ }^{39}$ In early pregnancy, increased estrogen, progesterone, and insulin favor lipid deposition and inhibit lipolysis. In late pregnancy, lipolysis and fat mobilization are promoted. The increases in plasma fatty acid and glycerol concentrations are consistent with mobilization of lipid stores for use by the fetus to aid growth and development. A recent study has investigated the pattern of changes in lipid profiles during pregnancy in obese and normal healthy-weight women. ${ }^{40} \mathrm{In}$ both groups, there were normal physiological increases in total cholesterol, triglycerides, very low density lipoprotein, and low density lipoprotein to mobilize lipids into the maternal circulation. However, the obese mothers had higher triglyceride levels than normal healthy-weight women at the start of pregnancy. Levels of triglycerides and triglyceriderich lipoproteins reached the same maximal level in both groups, suggesting less metabolic flexibility in the obese. In addition, the obese had an atherogenic low density lipoprotein subfraction phenotype, which may be important for their own future vascular health as well as health of the offspring.

\section{Placental modifications in obese pregnancy}

Modifications described in placentas of obese women include placental vascular function, changes of cell turnover, and increase of maternal inflammatory lesions (Figure 2). Placenta weight has been noted to increase with increasing maternal BMI. ${ }^{41}$ As previously discussed, the placenta is a source of inflammatory cytokines. Histological examination of placentas from obese women demonstrate a higher rate of maternal inflammatory response lesions (consistent 



\section{Placenta from obese pregnancy}

Figure 2 Placental modifications in obese pregnancy.

Notes: In obese pregnancy, reduced placental cell turnover (as demonstrated by lower detected levels of apoptosis marker) (cytokeratin M30) may contribute to overall larger size of placenta. Alterations of vessel muscularity and vasodilatation properties may affect placental oxygen and nutrient transport and place the fetus at risk. A higher rate of maternal inflammatory response lesions (consistent with chorioamnionitis) has also been reported.

with chorioamnionitis) compared with placentas from a normal-weight control group (43\% versus $3.6 \%, P<0.001) .{ }^{42}$ Examination of placental vasculature from obese placentas has revealed a greater degree of muscularity in the vessel walls $^{43}$ and reduced chorionic plate artery vasodilatation in response to nitric oxide donor sodium nitroprusside. ${ }^{44}$ Altered placental vascular function may adversely affect placental oxygen and nutrient transport and subsequently place the fetus at risk. ${ }^{44}$ A study of placental cell turnover identified decreased apoptosis with increasing maternal BMI, and in placentas of "large for gestational age" (LGA) infants. This suggests that lower rates of apoptosis in placentas of LGA infants may positively influence placental and fetal growth. ${ }^{45}$

\section{Early offspring outcomes: in utero Miscarriage}

Spontaneous first-trimester miscarriage affects 12\%-24\% of clinically recognized pregnancies, ${ }^{46}$ and $50 \%-85 \%$ of these are due to chromosomal abnormalities. ${ }^{47}$ Meta-analyses have shown that obesity is associated with an increased risk of miscarriage from both spontaneous ${ }^{48}$ and assisted concep- tion, via oocyte donation ${ }^{49}$ and after ovulation induction ${ }^{49}$ but not after in vitro fertilization or intra-cytoplasmic sperm injection. ${ }^{49}$ Obesity has also been identified as an independent risk factor for recurrent, unexplained miscarriage, ${ }^{50}$ with up to $73 \%$ increased risk of another miscarriage. ${ }^{51}$

The mechanism underlying the obesity-related increased risk of miscarriage is not known. Women who are obese or overweight (BMI $\geq 25 \mathrm{~kg} / \mathrm{m}^{2}$ ) have been shown to be significantly more likely to miscarry chromosomally normal embryos than women with BMI $<25 \mathrm{~kg} / \mathrm{m}^{2},{ }^{52,53}$ which suggests that alternative factors predispose this population to early pregnancy loss. Insulin resistance has been described as an independent risk factor for spontaneous miscarriage, ${ }^{54}$ and insulin-sensitizing agents such as metformin have been shown to reduce miscarriage rates. ${ }^{55}$

\section{Stillbirth}

Stillbirth rates are higher among obese women who have conceived naturally or through assisted reproductive techniques. A meta-analysis of nine studies ${ }^{56}$ suggested that obese women are at almost twice as high risk of stillbirth when compared with normal-weight women, and that the 
risk of stillbirth increases with increasing maternal BMI. The causal pathway for this association has not yet been defined. Most cohort studies have found the association of maternal obesity with stillbirth to be independent of potential confounding factors, including ethnicity, maternal age, parity, smoking, and history of preexisting diabetes or hypertensive disorders. Proposed explanations include maternal sleep apnea-associated fetal hypoxia and placental atherosclerosis secondary to maternal metabolic derangements. ${ }^{56}$ An alternative hypothesis includes abnormal trophoblast invasion with abnormal spiral arteries modification (ASAM). A study of 1,534 singleton pregnancy placentas found that the rate of ASAM was increased in women with a BMI $>30$ (odds ratio [OR] 1.8, 95\% confidence interval [CI] 1.1-3.0), and that the rate of intrauterine fetal death was significantly increased in ASAM (18\% versus 2.2\%; OR 8.2, 95\% CI 3.8-18.0).$^{57}$ Abnormal placental development itself could be related to stillbirth, or it could lead to other pregnancy complications leading to stillbirth, such as fetal growth restriction or placental abruption. ${ }^{57}$

The association of maternal obesity and stillbirth may also, in part, be related to different patterns of availability, uptake, and quality of antenatal health surveillance for obese and overweight women versus non-overweight women. Fetal growth and wellbeing assessments such as fundal height measurement and detection of fetal movements may also be less reliable in obese women. It is yet to be determined whether enhanced antenatal surveillance and monitoring would reduce these adverse outcomes in obese pregnant women. One thing that remains certain is that maternal obesity is a potentially modifiable risk factor for this devastating pregnancy outcome.

\section{Congenital abnormalities}

Maternal obesity is associated with an increased risk of congenital malformations. The results of a systematic review and meta-analysis ${ }^{58}$ estimating the increased risk of pregnancies complicated by a number of defects are summarized in Table 1. The cause of the increased risk of abnormalities is unclear. Potential mechanisms may include deficiencies in folic acid, chronic hypoxia, as well as metabolic changes including maternal hyperglycemia, increased insulin resistance, and incremented circulating levels of triglycerides and uric acid as described above. Another possible contributor to this apparent increase in congenital abnormalities may relate to the relative difficulties with antenatal detection. Ultrasound scanning of obese pregnant women may lead to suboptimal visualization of fetal anatomy, ${ }^{59}$ lower detection
Table I Increased risk of congenital malformations in obese pregnancy

\begin{tabular}{ll}
\hline Congenital malformation & OR (95\% CI) \\
\hline Neural tube defects & $\mathrm{I} .87(\mathrm{I} .62-2.15)$ \\
Spina bifida & $2.24(\mathrm{I} .86-2.69)$ \\
Cardiovascular anomalies & $\mathrm{I} .30(\mathrm{I} . \mathrm{I}-\mathrm{I}-\mathrm{I} 5)$ \\
Septal anomalies & $\mathrm{I} .20(\mathrm{I} .09-1.3 \mathrm{I})$ \\
Cleft palate & $\mathrm{I} .23(\mathrm{I} .03-\mathrm{I} .47)$ \\
Cleft lip and palate & $\mathrm{I} .20(\mathrm{I} .03-1.40)$ \\
Anorectal atresia & $\mathrm{I} .48(\mathrm{I} .12-1.97)$ \\
Hydrocephaly & $\mathrm{I} .68(\mathrm{I} .19-2.36)$ \\
Limb reduction anomalies & $\mathrm{I} .34(\mathrm{I} .03-1.73)$ \\
\hline
\end{tabular}

Note: Increased risk of congenital malformations in offspring of obese mothers. Table adapted with permission from Stothard et al. ${ }^{58}$ Copyright (c) 2009. American Medical Association. All rights reserved.

Abbreviations: $\mathrm{Cl}$, confidence interval; $\mathrm{OR}$, odds ratio.

rates of structural abnormalities, and therefore an increased prevalence at birth.

\section{LGA}

Maternal obesity is associated with increased fetal growth, which can lead to infants being LGA. ${ }^{5}$ When compared with normal-weight women, obese women are at up to $72 \%$ increased risk of having an LGA baby independent of coexistent diabetes. ${ }^{60}$ In addition to being born LGA, anthropometric measurements of neonates born to a cohort of lean and obese women demonstrated that maternal obesity is associated with altered neonatal body composition, with a significantly higher fat mass and a higher percentage body fat. ${ }^{61}$

LGA infants are predisposed to a variety of obstetric and neonatal outcomes, largely due to potential difficulties during labor and delivery, including shoulder dystocia and brachial plexus injury. ${ }^{62,63}$ The prediction of pregnancies at risk of pathological overgrowth is difficult. ${ }^{64}$ In the neonatal period, macrosomic infants are predisposed to electrolyte and metabolic disturbances, such as hypoglycemia, hyperbilirubinemia, and hypomagnesemia. ${ }^{65}$ In the long-term, infants that are at the highest end of the distribution for weight or BMI are more likely than other infants to be obese in childhood, adolescence, and early adulthood, ${ }^{66}$ and are at risk of cardiovascular and metabolic complications later in life. ${ }^{67,68}$ Potentially modifiable predictors of birth weight include maternal weight, gestational weight gain, gestational age at birth, and maternal glucose metabolism.

An interesting paradox exists between maternal obesity and intrauterine growth restriction, with some reports that the offspring of obese women are also at an increased risk of being growth restricted in utero (unrelated to preeclampsia). ${ }^{69}$ Furthermore, the Danish National Birth Cohort also identified 
a reduction in median birth weight of stillborn babies compared with live births in the obese women. This suggests that unrecognized fetal growth restriction may complicate the pregnancies of a subpopulation of obese women. ${ }^{70}$ Mechanisms underlying these findings are not known but may be related to poor placental function.

\section{Early offspring outcomes: intrapartum Delayed labor}

Post-term ( $>42$ weeks' gestation) as well as prolonged pregnancies ( $>41$ weeks' gestation) have been associated with multiple adverse neonatal outcomes, and increased risk of intervention at delivery. ${ }^{71}$ Retrospective populationbased cohort studies have reported that higher maternal BMI is associated with prolonged gestation at term at $>40$ weeks', $>41$ weeks', and $>42$ weeks' gestation. ${ }^{72-74}$ In the largest of these studies, ${ }^{74}$ analysis of $1,176,131$ singleton deliveries at $\geq 42$ weeks of gestation, women with a BMI of $\geq 30 \mathrm{~kg} / \mathrm{m}^{2}$ were found to be at a $60 \%$ increased risk of post-term delivery. ${ }^{74}$

\section{Shoulder dystocia and birth trauma}

Shoulder dystocia is an uncommon complication that occurs in $0.6 \%-1.4 \%$ of all vaginal vertex births. ${ }^{75,76}$ It can lead to bruising, fractured clavicle, transient or permanent brachial plexus injury, and hypoxic brain damage. The strongest predictor of shoulder dystocia has been reported to be macrosomia (birth weight $>4,000 \mathrm{~g}$ ), ${ }^{77}$ for which maternal obesity has been well described as an independent risk factor. However, when adjusting for confounding variables, maternal obesity has not been found to be significant as an independent risk factor for shoulder dystocia, ${ }^{77}$ suggesting birth size rather than maternal obesity per se is the key risk for this delivery complication.

A case report of shoulder dystocia in a morbidly obese patient suggested that due to both fetal macrosomia and a relative excess of fat in the pelvis, routine maneuvers for shoulder dystocia, such as McRoberts' position and suprapubic pressure, may be ineffective in obese women. It therefore recommended early resort to the internal rotatory maneuvers or extraction of the posterior arm during shoulder dystocia. ${ }^{78}$

\section{Early offspring outcomes: neonatal Neonatal unit (NNU) admissions}

Offspring from overweight or obese mothers appear to be at up to $38 \%$ increased risk of being admitted to the NNU than the offspring of mothers with a normal BMI. ${ }^{4,79,80}$ In a recent, large population-based analysis comparing NNU admission rate in obese and lean women from 38,675 consecutive births, maternal obesity was associated with increased risk of NNU admission. NNU admission was more common in women who labored when compared with those who were delivered by elective cesarean section (spontaneous labor, OR [95\% CI] 1.45 [1.21-1.73]; induction of labor, OR 1.34 [1.10-1.63]; elective cesarean section, OR 1.18 [0.86-1.63]), compared with women with a normal BMI. ${ }^{80}$ In terms of Apgar scores at birth, babies of obese mothers have been reported to have a $31 \%$ excess risk of having a low Apgar score (defined at $<7$ at 1 minute) (adjusted OR 1.31 [1.15-1.49]). Despite this, hypoglycemia is the only reason for admission to the NNU that has been found to be increased in babies from obese mothers. ${ }^{81}$ This may suggest that admission of babies from obese mothers to the NNU may be more likely to be due to an indication for increased surveillance rather than due to severe illness. Within the neonatal ward cohort, they seem to be the healthiest. ${ }^{81}$

\section{Breastfeeding}

A systematic review of nineteen studies reported that maternal obesity is associated with a decreased intention of breastfeeding, a shortened duration of breastfeeding, a less adequate milk supply, and a delayed onset of lactation (defined as onset after 72 hours post-partum). ${ }^{82}$ It has been suggested that because obese women tend to have larger breasts, this may be a mechanical barrier to breastfeeding and could contribute to a negative influence on the milk production and secretion. Obese women have also been found to report more difficulties with breastfeeding such as cracked nipples, fatigue, or difficulty initiating feeding at 1 month and 3 months postpartum, when compared with normal-weight women. ${ }^{83}$

\section{Longer-term offspring outcomes}

The Barker hypothesis states that environmental influences acting in fetal life are reflected in impaired growth and development which permanently affect structure and metabolism, leading to increased risk of metabolic disease later in life. ${ }^{84}$ This hypothesis has mainly focused on under-nutrition in the pregnant mother. However, during obese pregnancy, it has been suggested that the increased nutrient supply may lead to a response by the fetus to "program" its organs and tissues in a way that translates to long-term alterations to their function. ${ }^{85}$ This has been termed the "developmental over-nutrition" hypothesis. ${ }^{86}$ There is a growing body of evidence that there is a long-term relationship between 
maternal obesity with cardio-metabolic health in adulthood of the offspring.

However, in human studies, it is almost impossible to separate prenatal "programming" influences of maternal obesity on offspring outcomes from shared family characteristics, genetics, and postnatal environmental or lifestyle characteristics. Lifestyle factors such as current levels of obesity, behavior, activity, and diet are often considered as confounding factors. Indeed, there is much evidence for clustering of lifestyle factors, such as diet and exercise within families. ${ }^{87-89}$ Ongoing cohort studies with detailed characterization of women during pregnancy as well as infants in the post-partum period may help disentangle prenatal effects from postnatal effects. Studies involving siblings have also been used in an attempt to separate out intrauterine events from shared environmental and genetic factors. A prospective cohort study of 146,894 individuals from 136,050 families compared within-sibling and between-nonsibling associations of maternal weight gain on offspring BMI. ${ }^{90}$ This study found an independent influence of maternal obesity on offspring obesity, suggesting a programming mechanism. However, another sibling study found that shared familial traits may have a greater influence than maternal obesity on offspring $\mathrm{BMI},{ }^{87}$ highlighting the difficulties of distinguishing intrauterine influences from postnatal influences in humans.

\section{Offspring obesity}

Maternal obesity and its association with an increased risk of childhood and adult obesity among offspring has been well documented. ${ }^{11,91}$ Macrosomia and excess gestational weight gain are the strongest predictors of higher BMI at 1 year of age, and BMI at 1 year of age is predictive of weight status at ages 5-8 years. ${ }^{92}$ The effect of obesity during pregnancy on offspring risk of obesity appears to be independent of maternal diabetes. ${ }^{61}$ The Jerusalem Perinatal Family Follow-up Study showed that maternal BMI was independently and positively associated with increased offspring adiposity at age 32 years, ${ }^{93}$ and that these associations were significant when separated from "shared environment" and "postnatal lifestyle" factors. This would support a programming influence of maternal obesity on offspring obesity.

Further evidence that maternal obesity programs offspring obesity comes from another sibling study using a cohort of mothers who underwent surgical interventions for obesity. ${ }^{94}$ The authors observed the effects of dramatically altered BMI in the same women during subsequent pregnancies; thus, the potential influence of genetics and shared environment on offspring health were minimized. Offspring born before surgical intervention had significantly higher bodyweights at 12 years and at 21-25 years than offspring born after the surgery, in principle supporting the hypothesis that obesity has long-term influences on offspring bodyweight and BMI independent of genetic, environmental and lifestyle factors. ${ }^{94}$

\section{Offspring insulin resistance}

Maternal obesity and its association with offspring insulin resistance (which is a precursor for type 2 diabetes) has been reported at up to 20 years of age. Newborn babies of obese mothers have been found to have increased insulin resistance, as estimated by the homeostatic model assessment of insulin resistance. ${ }^{91}$ Data from the Hyperglycemia and Adverse Pregnancy Outcome (HAPO) study, which found an association between increased maternal BMI and fetal hyperinsulinemia (independent of maternal glycemia) support this observation. ${ }^{95}$ This association has also been found to persist at offspring age of 11 years ${ }^{66}$ and at age 20 years. ${ }^{96}$ Taken together, these data are supportive of a link between maternal obesity and altered offspring glucose-insulin homeostasis.

\section{Offspring hypertension and lipid profile}

The Jerusalem Perinatal Family Follow-up Study showed that maternal obesity was independently correlated with higher systolic and diastolic blood pressure in offspring at age 17 years ${ }^{97}$ and at age 32 years. ${ }^{93}$ In this same cohort, maternal BMI was also significantly associated with lower high density lipoproteins at age 32 years. ${ }^{93}$ These associations were significant when separated from "shared environment" and "postnatal lifestyle" factors. This would support a programming influence of maternal obesity on offspring obesity. This study did not assess the influence of directly measured genetic factors to the observed associations. ${ }^{93}$

\section{Long-term risk of cardiovascular disease for offspring}

There is accumulating evidence supporting a link between maternal obesity and offspring obesity and cardiometabolic risk factors. ${ }^{11}$ Whether or not this translates into long-term increased risk of cardiovascular disease and death for the offspring has been harder to investigate due to a lack of suitable cohorts with available data on maternal weight during pregnancy and with long enough follow-up of the offspring. ${ }^{98}$ There have only been two published studies reporting death from coronary heart disease. ${ }^{98,99}$ 
In 1997, a study of 3,002 Finnish men reported increased death from coronary heart disease in those who were thin at birth and whose mothers had an increased BMI during pregnancy. However, this finding was restricted to mothers who were of short stature. ${ }^{99}$ We recently investigated the relationship between maternal obesity and premature adult mortality in 37,709 offspring from obese mothers. ${ }^{98}$ Overall, offspring of obese mothers were at a $40 \%$ increased risk of premature death (death $<55$ years) from all causes, and at $29 \%$ increased risk of death due to cardiovascular disease. The risk was independent of current socioeconomic status. As only $4 \%$ of mothers in this study were obese, far fewer than current obesity levels, these findings are alarming. Further studies are needed to understand the underlying mechanisms and to determine whether the adverse effects of maternal obesity can be modified in childhood and adulthood by lifestyle changes.

\section{Other disease risk for offspring}

Maternal obesity has been linked with offspring developing other diseases such as asthma and neurodevelopmental disorders. There may also be a relationship between maternal obesity and the risk of some cancers.

\section{Asthma}

A cohort study of 38,874 mother-child pairs from the Danish National Birth Cohort found that maternal BMI $>35 \mathrm{~kg} / \mathrm{m}^{2}$ was associated with an increased risk of severe asthma at age 7 years (87\% and 97\%, respectively). ${ }^{100}$ A Swedish database study of offspring of women who were obese during pregnancy demonstrated a clear, dose-response relationship between the degree of maternal obesity during early pregnancy and increased risk of asthma in the child up to 13 years, but in boys $>13$ years. ${ }^{101}$ A Finnish cohort of 6,945 adolescents found that maternal BMI was a significant predictor of asthma in offspring at age $15-16$ years. ${ }^{102}$ The underlying mechanisms for these associations are not known. Maternal BMI and gestational weight gain were not associated with atopic eczema and hay fever, suggesting that pathways may be nonallergenic, ${ }^{100}$ and a lack of effect in sibling-pair analysis in this study favors genetic and shared environment risk factors to explain this association rather than intrauterine programming. ${ }^{101}$

\section{Neurodevelopment}

Maternal obesity has been associated with an increased risk of developing autism spectrum disorders (1.67 [1.10-2.56]) and developmental delay $(2.08$ [1.20-3.61] $) .{ }^{103}$ These findings raise concerns that these maternal conditions may be associated with neurodevelopmental problems in children, and therefore could have serious public health implications. Observational evidence suggests that increased maternal BMI is an independent risk factor for schizophrenia in offspring, when controlling for other potentially confounding maternal characteristics. ${ }^{104}$ This study did not investigate the relationship between maternal BMI and proximal determinants of neurodevelopmental problems such as maternal nutrition, prenatal toxin exposures, metabolic factors and obstetric complications.

\section{Cancer}

The effects of the positive feedback loop of adiposity from obese mothers to the child may increase the risk of some cancers for the offspring, ${ }^{105}$ with which birth weight is positively associated. ${ }^{106,107}$ Among childhood cancers, birth weight is positively associated with increased risk of neuroblastoma ${ }^{108}$ and leukemia. ${ }^{109-111}$ The risk of prostate ${ }^{112,113}$ and testicular ${ }^{114,115}$ cancers in men is positively associated with birth weight, and in women, there is a modest positive correlation between birth weight and breast cancer in adulthood. ${ }^{116-119}$ More studies are needed to investigate whether there are additional independent effects of maternal obesity, over and above the associations with birth weight, on offspring cancer risk.

\section{Conclusion}

Maternal obesity is a potentially modifiable risk factor for adverse outcomes that can occur during pregnancy and the neonatal period. There is emerging evidence to suggest that maternal obesity also has longer-lasting effects for the offspring, including increased risk of developing cardiovascular risk factors and disease. The physiological changes during pregnancy including increased inflammatory cytokines with associated insulin resistance, resulting in increased nutrient supply to the fetus may contribute to this risk with compensatory fetal hyperinsulinemia, increased fetal adiposity, and lifelong increased cardiometabolic risk. Evidence in support of a programming effect on the offspring of obese women would suggest there is a resultant positive loop effect on the prevalence of obesity, increasing the magnitude of the health care challenges posed by obesity. In an age where obesity has been described as a new worldwide epidemic, further work to understand more about the effects of maternal obesity for offspring is crucial. 


\section{Acknowledgments}

LIS is funded by Tommys. We acknowledge both Tommys and the British Heart Foundation.

\section{Disclosure}

The authors have no conflicts of interest to declare.

\section{References}

1. Linne Y. Effects of obesity on women's reproduction and complications during pregnancy. Obes Rev. 2004;5(3):137-143.

2. Fitzsimons KJ, Modder J, Centre for M, Child E. Setting maternity care standards for women with obesity in pregnancy. Semin Fetal Neonatal Med. 2010;15(2):100-107.

3. Galliano D, Bellver J. Female obesity: short- and long-term consequences on the offspring. Gynecol Endocrinol. 2013;29(7):626-631.

4. Vasudevan C, Renfrew M, McGuire W. Fetal and perinatal consequences of maternal obesity. Arch Dis Child Fetal Neonatal Ed. 2011;96(5):F378-F382.

5. Sebire NJ, Jolly M, Harris JP, et al. Maternal obesity and pregnancy outcome: a study of 287,213 pregnancies in London. Int J Obes Relat Metab Disord. 2001;25(8):1175-1182.

6. Dinatale A, Ermito S, Fonti I, et al. Obesity and fetal-maternal outcomes. J Prenat Med. 2010;4(1):5-8.

7. Dixit A, Girling JC. Obesity and pregnancy. J Obstet Gynaecol. 2008;28(1):14-23.

8. Usha Kiran TS, Hemmadi S, Bethel J, Evans J. Outcome of pregnancy in a woman with an increased body mass index. BJOG. 2005;112(6) 768-772.

9. Drake AJ, Seckl JR. Transmission of programming effects across generations. Pediatr Endocrinol Rev. 2011;9(2):566-578.

10. Li M, Sloboda DM, Vickers MH. Maternal obesity and developmental programming of metabolic disorders in offspring: evidence from animal models. Exp Diabetes Res. 2011;2011:592408.

11. Drake AJ, Reynolds RM. Impact of maternal obesity on offspring obesity and cardiometabolic disease risk. Reproduction. 2010;140(3):387-398.

12. Galic S, Oakhill JS, Steinberg GR. Adipose tissue as an endocrine organ. Mol Cell Endocrinol. 2010;316(2):129-139.

13. Avram MM, Avram AS, James WD. Subcutaneous fat in normal and diseased states 3. Adipogenesis: from stem cell to fat cell. $J$ Am Acad Dermatol. 2007;56(3):472-492.

14. de Ferranti S, Mozaffarian D. The perfect storm: obesity, adipocyte dysfunction, and metabolic consequences. Clin Chem. 2008;54(6): 945-955.

15. Lacroix M, Battista MC, Doyon M, et al. Lower adiponectin levels at first trimester of pregnancy are associated with increased insulin resistance and higher risk of developing gestational diabetes mellitus. Diabetes Care. 2013;36(6):1577-1583.

16. Retnakaran R, Hanley AJ, Raif N, et al. Adiponectin and beta cell dysfunction in gestational diabetes: pathophysiological implications. Diabetologia. 2005;48(5):993-1001.

17. Catalano PM, Hoegh M, Minium J, et al. Adiponectin in human pregnancy: implications for regulation of glucose and lipid metabolism. Diabetologia. 2006;49(7):1677-1685.

18. Challier JC, Basu S, Bintein T, et al. Obesity in pregnancy stimulates macrophage accumulation and inflammation in the placenta. Placenta. 2008;29(3):274-281.

19. Dowling D, McAuliffe FM. The molecular mechanisms of offspring effects from obese pregnancy. Obes Facts. 2013;6(2): 134-145.

20. Chen X, Scholl TO. Ethnic differences in C-peptide/insulin/glucose dynamics in young pregnant women. $J$ Clin Endocrinol Metab. 2002;87(10):4642-4646.
21. Retnakaran R, Qi Y, Sermer M, Connelly PW, Zinman B, Hanley AJ. Pre-gravid physical activity and reduced risk of glucose intolerance in pregnancy: the role of insulin sensitivity. Clin Endocrinol (Oxf). 2009;70(4):615-622.

22. McIntyre HD, Chang AM, Callaway LK, et al. Hormonal and metabolic factors associated with variations in insulin sensitivity in human pregnancy. Diabetes Care. 2010;33(2):356-360.

23. Zeyda M, Stulnig TM. Obesity, inflammation, and insulin resistance a mini-review. Gerontology. 2009;55(4):379-386.

24. Hivert MF, Sullivan LM, Fox CS, et al. Associations of adiponectin, resistin, and tumor necrosis factor-alpha with insulin resistance. J Clin Endocrinol Metab. 2008;93(8):3165-3172.

25. Sivan E, Homko CJ, Chen X, Reece EA, Boden G. Effect of insulin on fat metabolism during and after normal pregnancy. Diabetes. 1999;48(4):834-838.

26. Ramsay JE, Ferrell WR, Crawford L, Wallace AM, Greer IA, Sattar N. Maternal obesity is associated with dysregulation of metabolic, vascular, and inflammatory pathways. J Clin Endocrinol Metab. 2002;87(9): 4231-4237.

27. Duthie L, Reynolds RM. Changes in the maternal hypothalamicpituitary-adrenal axis in pregnancy and postpartum: influences on maternal and fetal outcomes. Neuroendocrinology. 2013;98(2): $106-115$.

28. Gangestad SW, Caldwell Hooper AE, Eaton MA. On the function of placental corticotropin-releasing hormone: a role in maternal-fetal conflicts over blood glucose concentrations. Biol Rev Camb Philos Soc. 2012;87(4):856-873.

29. Lacroix M, Kina E, Hivert MF. Maternal/fetal determinants of insulin resistance in women during pregnancy and in offspring over life. Curr Diab Rep. 2013;13(2):238-244.

30. Duggleby SL, Jackson AA. Relationship of maternal protein turnover and lean body mass during pregnancy and birth length. Clin Sci (Lond). 2001;101(1):65-72.

31. Regnault TR, Friedman JE, Wilkening RB, Anthony RV, Hay WW Jr. Fetoplacental transport and utilization of amino acids in IUGR a review. Placenta. 2005;26 Suppl A:S52-S62.

32. Avagliano L, Garo C, Marconi AM. Placental amino acids transport in intrauterine growth restriction. J Pregnancy. 2012;2012:972562.

33. Duggleby SL, Jackson AA. Higher weight at birth is related to decreased maternal amino acid oxidation during pregnancy. Am J Clin Nutr. 2002;76(4):852-857.

34. Chevalier S, Marliss EB, Morais JA, Lamarche M, Gougeon R. Whole-body protein anabolic response is resistant to the action of insulin in obese women. Am J Clin Nutr. 2005;82(2):355-365.

35. Nelson SM, Matthews P, Poston L. Maternal metabolism and obesity: modifiable determinants of pregnancy outcome. Hum Reprod Update. 2010;16(3):255-275.

36. Jansson N, Rosario FJ, Gaccioli F, et al. Activation of placental mTOR signaling and amino acid transporters in obese women giving birth to large babies. J Clin Endocrinol Metab. 2013;98(1):105-113.

37. Jones HN, Jansson T, Powell TL. IL-6 stimulates system A amino acid transporter activity in trophoblast cells through STAT3 and increased expression of SNAT2. Am J Physiol Cell Physiol. 2009;297(5): C1228-C1235.

38. Denison FC, Roberts KA, Barr SM, Norman JE. Obesity, pregnancy, inflammation, and vascular function. Reproduction. 2010;140(3): 373-385.

39. Higa R, Jawerbaum A. Intrauterine effects of impaired lipid homeostasis in pregnancy diseases. Curr Med Chem. 2013;20(18):2338-2350.

40. Meyer BJ, Stewart FM, Brown EA, et al. Maternal obesity is associated with the formation of small dense LDL and hypoadiponectinemia in the third trimester. $J$ Clin Endocrinol Metab. 2013;98(2): 643-652.

41. Swanson LD, Bewtra C. Increase in normal placental weights related to increase in maternal body mass index. J Matern Fetal Neonatal Med. 2008;21(2):111-113. 
42. Bar J, Schreiber L, Saruhanov E, Ben-Haroush A, Golan A, Kovo M. Placental histopathological findings in obese and nonobese women with complicated and uncomplicated pregnancies. Arch Gynecol Obstet. 2012;286(6):1343-1347.

43. Roberts KA, Riley SC, Reynolds RM, et al. Placental structure and inflammation in pregnancies associated with obesity. Placenta. 2011;32(3):247-254.

44. Hayward CE, Higgins L, Cowley EJ, et al. Chorionic plate arterial function is altered in maternal obesity. Placenta. 2013;34(3):281-287.

45. Higgins L, Mills TA, Greenwood SL, Cowley EJ, Sibley CP, Jones RL. Maternal obesity and its effect on placental cell turnover. J Matern Fetal Neonatal Med. 2013;26(8):783-788.

46. Prendeville W. Epidemiology of miscarriage. In: Gradzinskas JG, O'Brien PMS editors. Problems in Early Pregnancy: Advances in Diagnosis and Management. RCOG Press; 1997:1-15.

47. van den Berg MM, van Maarle MC, van Wely M, Goddijn M. Genetics of early miscarriage. Biochim Biophys Acta. 2012;1822(12):1951-1959.

48. Boots C, Stephenson MD. Does obesity increase the risk of miscarriage in spontaneous conception: a systematic review. Semin Reprod Med. 2011;29(6):507-513.

49. Metwally M, Ong KJ, Ledger WL, Li TC. Does high body mass index increase the risk of miscarriage after spontaneous and assisted conception? A meta-analysis of the evidence. Fertil Steril. 2008;90(3): 714-726.

50. Lashen H, Fear K, Sturdee DW. Obesity is associated with increased risk of first trimester and recurrent miscarriage: matched case-control study. Hum Reprod. 2004;19(7):1644-1646.

51. Lo W, Rai R, Hameed A, Brailsford SR, Al-Ghamdi AA, Regan L. The effect of body mass index on the outcome of pregnancy in women with recurrent miscarriage. J Family Community Med. 2012;19(3):167-171.

52. Landres IV, Milki AA, Lathi RB. Karyotype of miscarriages in relation to maternal weight. Hum Reprod. 2010;25(5):1123-1126.

53. Kroon B, Harrison K, Martin N, Wong B, Yazdani A. Miscarriage karyotype and its relationship with maternal body mass index, age, and mode of conception. Fertil Steril. 2011;95(5):1827-1829.

54. Tian L, Shen H, Lu Q, Norman RJ, Wang J. Insulin resistance increases the risk of spontaneous abortion after assisted reproduction technology treatment. J Clin Endocrinol Metab. 2007;92(4):1430-1433.

55. Glueck CJ, Phillips H, Cameron D, Sieve-Smith L, Wang P. Continuing metformin throughout pregnancy in women with polycystic ovary syndrome appears to safely reduce first-trimester spontaneous abortion: a pilot study. Fertil Steril. 2001;75(1):46-52.

56. Chu SY, Kim SY, Lau J, et al. Maternal obesity and risk of stillbirth: a metaanalysis. Am J Obstet Gynecol. 2007;197(3):223-228.

57. Avagliano L, Bulfamante GP, Morabito A, Marconi AM. Abnormal spiral artery remodelling in the decidual segment during pregnancy: from histology to clinical correlation. J Clin Pathol. 2011;64(12): 1064-1068

58. Stothard KJ, Tennant PW, Bell R, Rankin J. Maternal overweight and obesity and the risk of congenital anomalies: a systematic review and meta-analysis. JAMA. 2009;301(6):636-650.

59. Hendler I, Blackwell SC, Bujold E, et al. Suboptimal second-trimester ultrasonographic visualization of the fetal heart in obese women: should we repeat the examination? J Ultrasound Med. 2005;24(9):1205-1209; quiz $10-11$.

60. Ehrenberg HM, Mercer BM, Catalano PM. The influence of obesity and diabetes on the prevalence of macrosomia. Am J Obstet Gynecol. 2004;191(3):964-968.

61. Sewell MF, Huston-Presley L, Super DM, Catalano P. Increased neonatal fat mass, not lean body mass, is associated with maternal obesity. Am J Obstet Gynecol. 2006;195(4):1100-1103.

62. Baskett TF, Allen AC. Perinatal implications of shoulder dystocia. Obstet Gynecol. 1995;86(1):14-17.

63. Walsh JM, Kandamany N, Ni Shuibhne N, Power H, Murphy JF, O'Herlihy C. Neonatal brachial plexus injury: comparison of incidence and antecedents between 2 decades. Am J Obstet Gynecol. 2011;204(4):324. e1-e6.
64. Walsh JM, McAuliffe FM. Prediction and prevention of the macrosomic fetus. Eur J Obstet Gynecol Reprod Biol. 2012;162(2):125-130.

65. Nold JL, Georgieff MK. Infants of diabetic mothers. Pediatr Clin North Am. 2004;51(3):619-637, viii.

66. Boney CM, Verma A, Tucker R, Vohr BR. Metabolic syndrome in childhood: association with birth weight, maternal obesity, and gestational diabetes mellitus. Pediatrics. 2005;115(3):e290-e296.

67. Hermann GM, Dallas LM, Haskell SE, Roghair RD. Neonatal macrosomia is an independent risk factor for adult metabolic syndrome. Neonatology. 2010;98(3):238-244.

68. Ornoy A. Prenatal origin of obesity and their complications: gestational diabetes, maternal overweight and the paradoxical effects of fetal growth restriction and macrosomia. Reprod Toxicol. 2011;32(2): 205-212.

69. Rajasingam D, Seed PT, Briley AL, Shennan AH, Poston L. A prospective study of pregnancy outcome and biomarkers of oxidative stress in nulliparous obese women. Am J Obstet Gynecol. 2009;200(4):395. e1-e9.

70. Nohr EA, Bech BH, Davies MJ, Frydenberg M, Henriksen TB, Olsen J. Prepregnancy obesity and fetal death: a study within the Danish National Birth Cohort. Obstet Gynecol. 2005;106(2):250-259.

71. Norwitz ER, Snegovskikh VV, Caughey AB. Prolonged pregnancy: when should we intervene? Clin Obstet Gynecol. 2007;50(2):547-557.

72. Stotland NE, Washington AE, Caughey AB. Prepregnancy body mass index and the length of gestation at term. Am J Obstet Gynecol. 2007;197(4):378. e1-e5.

73. Caughey AB, Stotland NE, Washington AE, Escobar GJ. Who is at risk for prolonged and postterm pregnancy? Am J Obstet Gynecol. 2009;200(6):683. e1-e5.

74. Roos N, Sahlin L, Ekman-Ordeberg G, Kieler H, Stephansson O. Maternal risk factors for postterm pregnancy and cesarean delivery following labor induction. Acta Obstet Gynecol Scand. 2010;89(8): 1003-1010.

75. Beall MH, Spong C, McKay J, Ross MG. Objective definition of shoulder dystocia: a prospective evaluation. Am J Obstet Gynecol. 1998;179(4):934-937.

76. Cohen BF, Penning S, Ansley D, Porto M, Garite T. The incidence and severity of shoulder dystocia correlates with a sonographic measurement of asymmetry in patients with diabetes. Am J Perinatol. 1999;16(4):197-201.

77. Robinson H, Tkatch S, Mayes DC, Bott N, Okun N. Is maternal obesity a predictor of shoulder dystocia? Obstet Gynecol. 2003;101(1):24-27.

78. Poggi SH, Spong CY, Allen RH. Prioritizing posterior arm delivery during severe shoulder dystocia. Obstet Gynecol. 2003;101(5 Pt 2): 1068-1072.

79. Hollowell J, Pillas D, Rowe R, Linsell L, Knight M, Brocklehurst P. The impact of maternal obesity on intrapartum outcomes in otherwise low risk women: secondary analysis of the Birthplace national prospective cohort study. BJOG. 2014;121(3):343-355.

80. Minsart AF, Buekens P, De Spiegelaere M, Englert Y. Neonatal outcomes in obese mothers: a population-based analysis. $B M C$ Pregnancy Childbirth. 2013;13:36.

81. Kalk P, Guthmann F, Krause K, et al. Impact of maternal body mass index on neonatal outcome. Eur J Med Res. 2009;14(5):216-222.

82. Turcksin R, Bel S, Galjaard S, Devlieger R. Maternal obesity and breastfeeding intention, initiation, intensity and duration: a systematic review. Matern Child Nutr. Epub August 20, 2012.

83. Mok E, Multon C, Piguel L, et al. Decreased full breastfeeding, altered practices, perceptions, and infant weight change of prepregnant obese women: a need for extra support. Pediatrics. 2008;121(5): e1319-e1324.

84. Barker DJ. The origins of the developmental origins theory. J Intern Med. 2007;261(5):412-417.

85. Lucas A. Programming by early nutrition in man. Ciba Found Symp. 1991;156:38-50; discussion 50-55.

86. Taylor PD, Poston L. Developmental programming of obesity in mammals. Exp Physiol. 2007;92(2):287-298. 
87. Branum AM, Parker JD, Keim SA, Schempf AH. Prepregnancy body mass index and gestational weight gain in relation to child body mass index among siblings. Am J Epidemiol. 2011;174(10):1159-1165.

88. Reilly JJ, Armstrong J, Dorosty AR, et al. Early life risk factors for obesity in childhood: cohort study. BMJ. 2005;330(7504):1357.

89. Rogers I; EURO-BLCS Study Group. The influence of birthweight and intrauterine environment on adiposity and fat distribution in later life. Int J Obes Relat Metab Disord. 2003;27(7):755-777.

90. Lawlor DA, Lichtenstein P, Fraser A, Langstrom N. Does maternal weight gain in pregnancy have long-term effects on offspring adiposity? A sibling study in a prospective cohort of 146,894 men from 136,050 families. Am J Clin Nutr. 2011;94(1):142-148.

91. Catalano PM, Presley L, Minium J, Hauguel-de Mouzon S. Fetuses of obese mothers develop insulin resistance in utero. Diabetes Care. 2009;32(6):1076-1080.

92. Lindberg SM, Adams AK, Prince RJ. Early predictors of obesity and cardiovascular risk among American Indian children. Matern Child Health J. 2012;16(9):1879-1886.

93. Hochner H, Friedlander Y, Calderon-Margalit R, et al. Associations of maternal prepregnancy body mass index and gestational weight gain with adult offspring cardiometabolic risk factors: the Jerusalem Perinatal Family Follow-up Study. Circulation. 2012;125(11):1381-1389.

94. Barisione M, Carlini F, Gradaschi R, Camerini G, Adami GF. Body weight at developmental age in siblings born to mothers before and after surgically induced weight loss. Surg Obes Relat Dis. 2012;8(4): 387-391.

95. Group HSCR, Metzger BE, Lowe LP, et al. Hyperglycemia and adverse pregnancy outcomes. N Engl J Med. 2008;358(19):1991-2002.

96. Mingrone G, Manco M, Mora ME, et al. Influence of maternal obesity on insulin sensitivity and secretion in offspring. Diabetes Care. 2008;31(9):1872-1876.

97. Laor A, Stevenson DK, Shemer J, Gale R, Seidman DS. Size at birth, maternal nutritional status in pregnancy, and blood pressure at age 17: population based analysis. BMJ. 1997;315(7106):449-453.

98. Reynolds RM, Allan KM, Raja EA, et al. Maternal obesity during pregnancy and premature mortality from cardiovascular event in adult offspring: follow-up of 1323275 person years. BMJ. 2013;347:f4539.

99. Forsen T, Eriksson JG, Tuomilehto J, Teramo K, Osmond C, Barker DJ. Mother's weight in pregnancy and coronary heart disease in a cohort of Finnish men: follow up study. BMJ. 1997;315(7112):837-840.

100. Harpsoe MC, Basit S, Bager P, et al. Maternal obesity, gestational weight gain, and risk of asthma and atopic disease in offspring: a study within the Danish National Birth Cohort. J Allergy Clin Immunol. 2013;131(4):1033-1040.

101. Lowe A, Braback L, Ekeus C, Hjern A, Forsberg B. Maternal obesity during pregnancy as a risk for early-life asthma. J Allergy Clin Immunol. 2011;128(5):1107-1109. e1-e2.

102. Patel SP, Rodriguez A, Little MP, et al. Associations between prepregnancy obesity and asthma symptoms in adolescents. J Epidemiol Community Health. 2012;66(9):809-814.
103. Krakowiak P, Walker CK, Bremer AA, et al. Maternal metabolic conditions and risk for autism and other neurodevelopmental disorders. Pediatrics. 2012;129(5):e1121-e1128.

104. Schaefer CA, Brown AS, Wyatt RJ, et al. Maternal prepregnant body mass and risk of schizophrenia in adult offspring. Schizophr Bull. 2000;26(2):275-286.

105. Simmen FA, Simmen RC. The maternal womb: a novel target for cancer prevention in the era of the obesity pandemic? Eur J Cancer Prev. 2011;20(6):539-548

106. Andersson SW, Bengtsson C, Hallberg L, et al. Cancer risk in Swedish women: the relation to size at birth. Br J Cancer. 2001;84(9): 1193-1198.

107. Ahlgren M, Wohlfahrt J, Olsen LW, Sorensen TI, Melbye M. Birth weight and risk of cancer. Cancer. 2007;110(2):412-419.

108. Harder T, Plagemann A, Harder A. Birth weight and risk of neuroblastoma: a meta-analysis. Int J Epidemiol. 2010;39(3):746-756.

109. Koifman S, Pombo-de-Oliveira MS. Brazilian Collaborative Study Group of Infant Acute Leukemia. High birth weight as an important risk factor for infant leukemia. Br J Cancer. 2008;98(3):664-667.

110. Caughey RW, Michels KB. Birth weight and childhood leukemia: a meta-analysis and review of the current evidence. Int $J$ Cancer. 2009;124(11):2658-2670.

111. Rangel M, Cypriano M, de Martino Lee ML, et al. Leukemia, non-Hodgkin's lymphoma, and Wilms tumor in childhood: the role of birth weight. Eur J Pediatr. 2010;169(7):875-881.

112. Eriksson M, Wedel H, Wallander MA, et al. The impact of birth weight on prostate cancer incidence and mortality in a population-based study of men born in 1913 and followed up from 50 to 85 years of age. Prostate. 2007;67(11):1247-1254.

113. Cnattingius S, Lundberg F, Sandin S, Gronberg H, Iliadou A. Birth characteristics and risk of prostate cancer: the contribution of genetic factors. Cancer Epidemiol Biomarkers Prev. 2009;18(9):2422-2426.

114. Michos A, Xue F, Michels KB. Birth weight and the risk of testicular cancer: a meta-analysis. Int J Cancer. 2007;121(5):1123-1131.

115. Ramlau-Hansen CH, Olesen AV, Parner ET, Sorensen HT, Olsen J. Perinatal markers of estrogen exposure and risk of testicular cancer: follow-up of 1,333,873 Danish males born between 1950 and 2002. Cancer Causes Control. 2009;20(9):1587-1592.

116. Xue F, Michels KB. Intrauterine factors and risk of breast cancer: a systematic review and meta-analysis of current evidence. Lancet Oncol. 2007;8(12):1088-1100.

117. Park SK, Kang D, McGlynn KA, et al. Intrauterine environments and breast cancer risk: meta-analysis and systematic review. Breast Cancer Res. 2008;10(1):R8.

118. Silva Idos S, De Stavola B, McCormack V; Collaborative Group on Pre-Natal Risk Factors and Subsequent Risk of Breast Cancer. Birth size and breast cancer risk: re-analysis of individual participant data from 32 studies. PLoS Med. 2008;5(9):e193.

119. Maehle BO, Vatten LJ, Tretli S. Birth length and weight as predictors of breast cancer prognosis. BMC Cancer. 2010;10:115.

Research and Reports in Neonatology

\section{Publish your work in this journal}

Research and Reports in Neonatology is an international, peer-reviewed, open access journal publishing original research, reports, editorials, reviews and commentaries on neonatal health. The manuscript management system is completely online and includes a very quick and fair

peer-review system. Visit http://www.dovepress.com/testimonials.php to read real quotes from published authors. 